\title{
Coded Simple Value Data Type
}

National Cancer Institute

\section{Source}

National Cancer Institute. Coded Simple Value Data Type. NCI Thesaurus. Code C95634.

A data type comprised of coded data in its simplest form. 